\title{
Overview of the Dutch science system
}

\section{CHEPS WORKING PAPER 04/2018}

Ben Jongbloed, Research associate, CHEPS (University of Twente)

Email: b.w.a.jongbloed@utwente.nl

Series Editor Contact:

Katharina Lemmens-Krug, Franziska Eckardt \& Paul Benneworth

Centre for Higher Education Policy Studies

University of Twente

P.O. Box 217

7500 AE Enschede

The Netherlands

T +3153-4896587

E k.lemmens-krug@utwente.nl

W www.utwente.nl/cheps 


\section{Table of Contents}

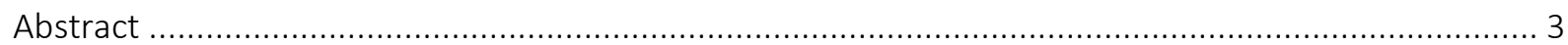

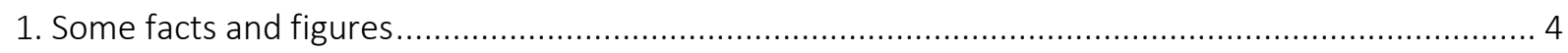

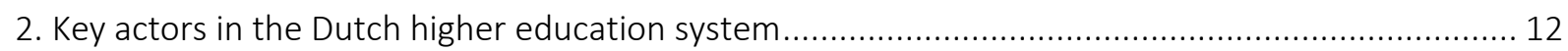

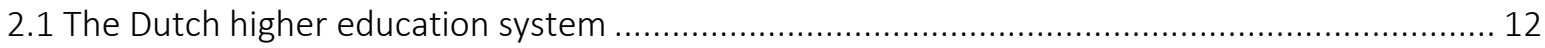

2.2 The bigger picture: key actors in the higher education and research system........................... 17

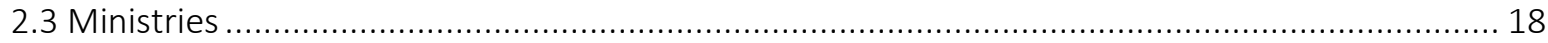

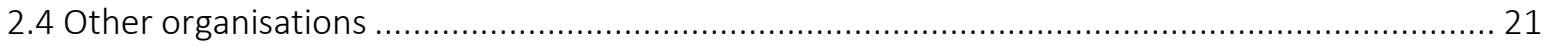

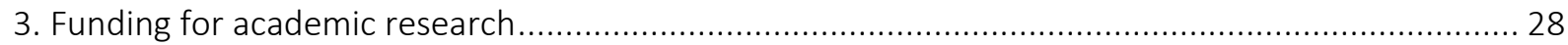

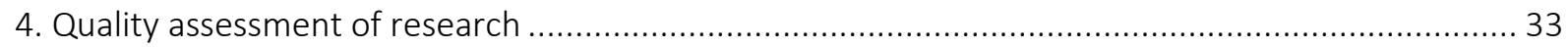

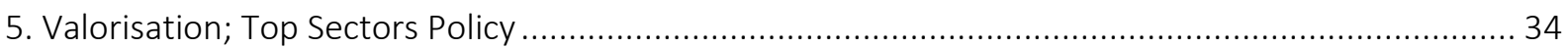

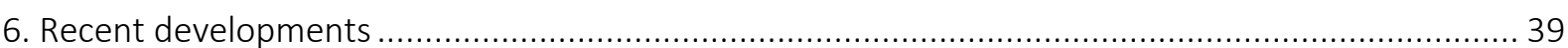

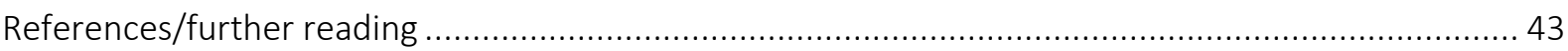




\section{Abstract}

This paper presents the Dutch higher education and research system. It describes the main actors, the framework conditions for science, and recent policies aimed at strengthening the science system of the Netherlands. It is mainly descriptive and meant to give a quick overview. Hyperlinks and additional literature are included for readers that wish to dig deeper.

Keywords: Higher education policy; Science system; Netherlands; Research; Innovation system; Governance 


\section{Some facts and figures}

The Netherlands (population: 17 million) is a highly developed knowledge-based economy, performing very well in many science, technology, innovation and competitiveness rankings. Its tertiary attainment (35\%) exceeds the EU and OECD averages. Like other countries it is more and more convinced of the importance of science for the quality of life - the search for solutions to the grand societal challenges. The Netherlands has an innovative business sector. Large Dutch multinationals are amongst the world's leading innovators. The country has very high rates of patenting activity and is typically among the world's leaders, owing to the presence of some large, globally networked and probably highly efficient $R \& D$ spenders. The business sector is very diverse, partly reflecting the Netherlands' role as a gateway to Europe and its large volume of re-exports. Alongside good export performance in high-technology sectors such as electronics and pharmaceuticals, the Dutch business sector exports strongly in sectors that are traditionally not considered knowledge-intensive or high-technology, notably in niches of agriculture and food products. The value of the country's agricultural exports is second only to America, a country 200 times the size of the Netherlands. The Netherlands are seeking to sell not only their food but also their expertise. The country is in the lead where it comes to improved farming techniques stressing sustainable and intensive food production.

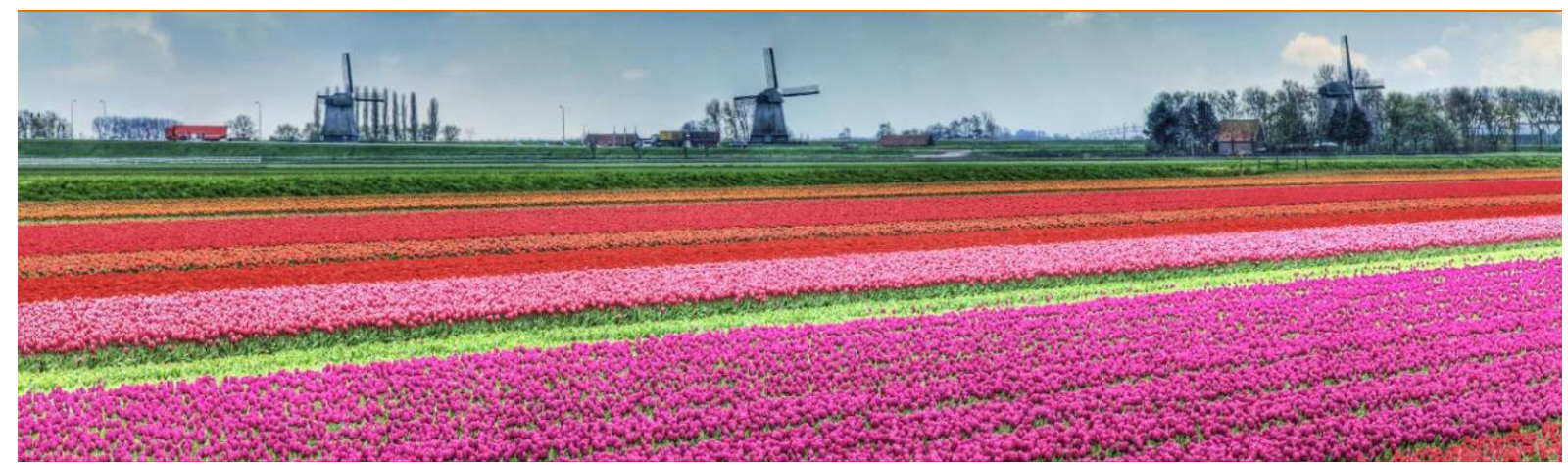

The share of the workforce employed in small and medium-sized enterprises (SMEs) is equal to the EU average (67\%). Relative to the EU average, Dutch SMEs are oriented more towards services than manufacturing. In the services sector, the Netherlands has traditional strengths in trade, transport and logistics, owing in part to its favourable geographical position. It is a major logistics hub, acting as a 
gateway to continental Europe and to the United Kingdom. The Rotterdam harbour and Schiphol airport are important centres of economic activity - also for their surrounding region. Transport, logistics, information technology (IT) and not least, finance, provide services that are crucial for the performance of other sectors, including manufacturing.

The Netherlands also enjoys moderately high shares of knowledge intensive employment (on the basis of their average propensity to employ tertiary graduates). Eurostat figures on the share of employment in industries classified as knowledge-intensive show a relatively high $38,1 \%$ (2015) for the Netherlands, roughly two percentage points over the EU average. This shows that the Netherlands possesses the human capital and the production structure that underpin strong innovation systems. A particular strength is the expansion of professional education in the universities of applied sciences (UAS), a level and type of education that is important for innovation.

The government has vowed to spend $2.5 \%$ of GDP in the year 2020 on R\&D (from both public and private sources). However, in 2017 the Netherlands was some 0.5 percentage points below this target (but still slightly higher than the OECD average).

Funding for R\&D comes from governments, but also from companies, other national sources and abroad (see picture below). Set against the size of the economy, the total financing for R\&D in the Netherlands increased slightly between 2011 and 2016, from 1.9 percent of gross domestic product (GDP) to 2.03 percent. This increase is mainly due to increased R\&D funding from abroad. The $2.03 \%$ of GDP is similar to the EU28 average. The direct government support for R\&D is expected to fall as a percentage of GDP from 2018 on the basis of the government's budget plans. In order to reach the internationally agreed R\&D intensity of $2.5 \%$ GDP in 2020 , a total extra investment of $€ 5.8$ billion would be required compared to 2016 . This will require 
additional expenditures that must come largely from the side of the companies, but also partly from the government. The ratio between public and private $R \& D$ investments is 1:1.5.

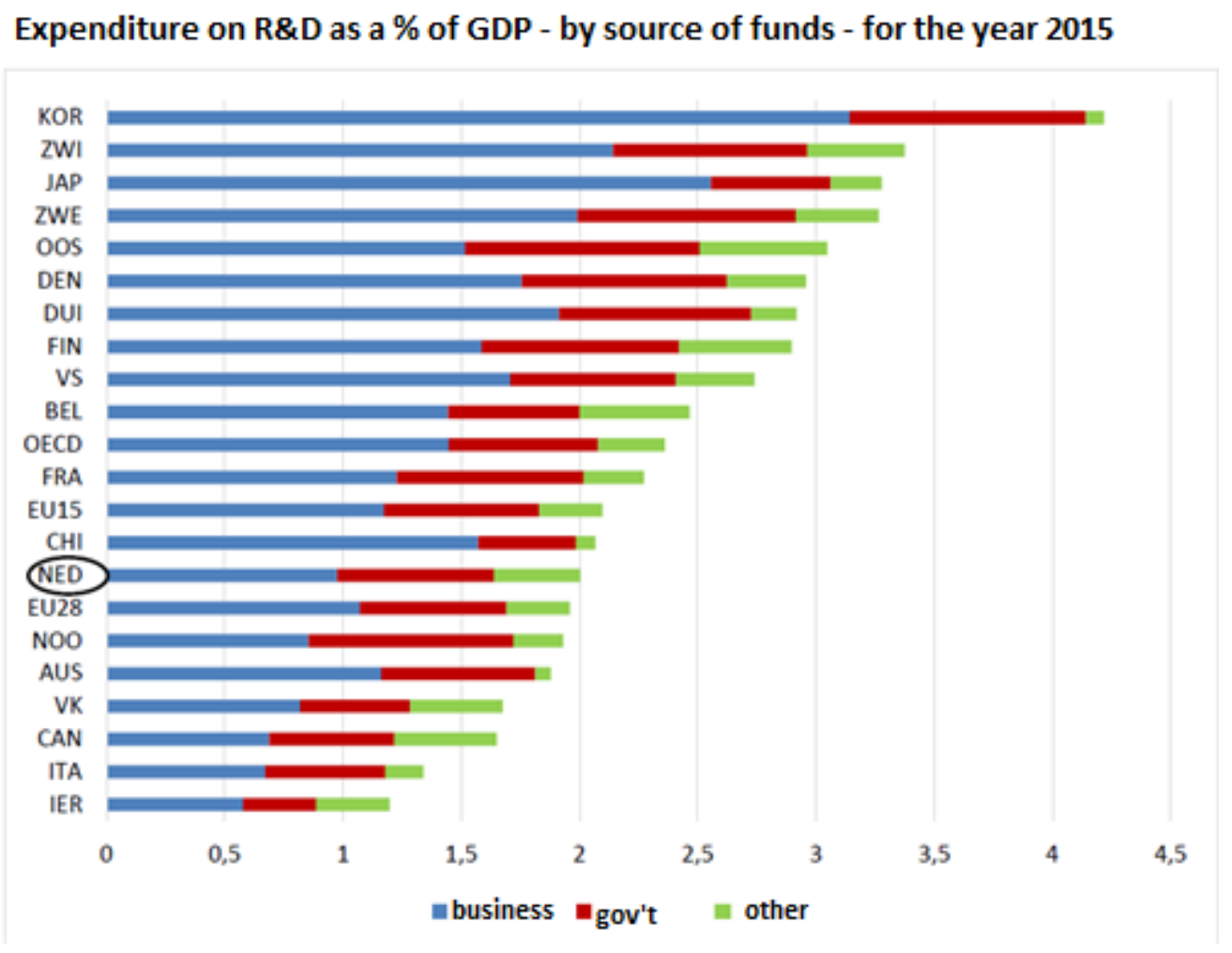

Source: Rathenau (https://www.rathenau.nl/nl/wetenschap-cijfers/)

The Netherlands is performing very well on almost all indicators for competitiveness and innovation. In the most recent edition of the World Competitiveness Report (Schwab 2017), the Netherlands is in fourth position (after Switzerland, the US and Singapore). On the European Innovation Scoreboard (EU, 2017), the Netherlands increased its performance. According to this scoreboard, the Netherlands is fourth in the group of six EU countries (with Germany, the UK, Finland, Denmark, and Sweden) known as 'innovation leaders'. The strengths of the Dutch Research \& Innovation system include its research system, a well-educated workforce, the quality of its scientific research institutions and strong linkages between business and science. Business expenditure in $R \& D$, however, remains relatively low in comparison to other countries in the Innovation Leader's group. 
The quality of the Dutch science base among other things is reflected in the number and quality of scientific publications. The percentage of scientific publications that is part of the top $10 \%$ most cited publications (14.5\%) is above the worldwide average (10.5\%); only the Swiss share $(15.7 \%)$ is higher. The Dutch research system is very open to cooperation with partners from abroad, meaning its researchers are well networked at international level. This is expressed in international scientific co-publications, public-private co-publications and new doctorate graduates.

Figure 1: Performance of EU Member States' innovation systems

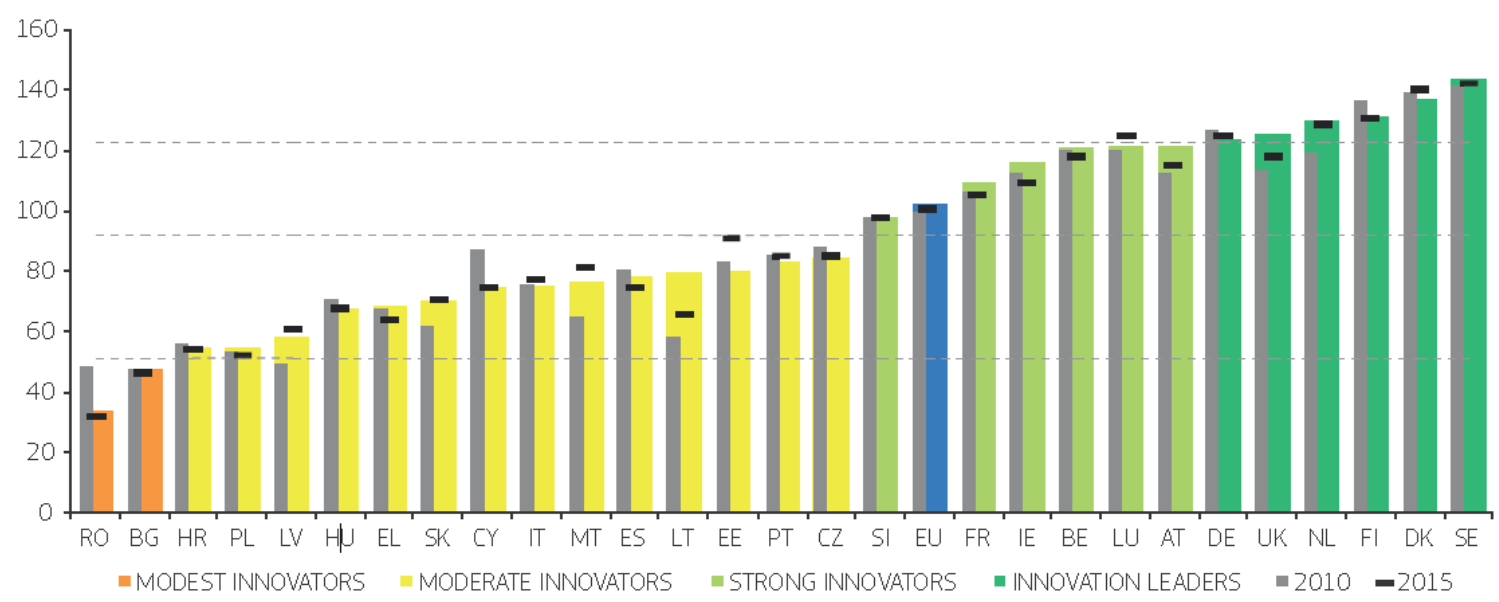

Coloured columns show Member States' performance in 2016, using the most recent data for 27 indicators, relative to that of the EU in 2010. The horizontal hyphens show performance in 2015, using the next most recent data for 27 indicators, relative to that of the EU in 2010 . Grey columns show Member States' performance in 2010 relative to that of the EU in 2010 . For all years the same measurement methodology has been used. The dashed lines show the threshold values between the performance groups in 2016, comparing Member States' performance in 2016 relative to that of the EU in 2016.

Source: European Innovation Scoreboard 2017 (European Commission)

In 2014 the OECD evaluated the innovation system of the Netherlands with the following strengths and weaknesses (OECD, 2014). The OECD observed the following strengths of the Dutch innovation system:

- A strong human resource base.

- A strong science base with strong research universities and public research institutes, excellent output in terms of the number and quality of scientific publications, and high productivity.

- A strong participation in European Framework Programmes and other international cooperative efforts and networks. 
- Innovative approaches, design, and delivery of innovation policy.

- A strong culture of evaluation.

Dutch research universities do well in international rankings. The Netherlands is one of the few countries where nearly all universities are listed in international rankings. Most rankings put the emphasis on research.

The picture below gives an impression of the performance of Dutch universities in certain rankings and the position of the Netherlands in general. This is done on the basis of the four most used rankings in the world:

- the (Shanghai) Academic Ranking of World Universities (ARWU)

- the Times Higher Education (THE) World Ranking

- the QS World University Rankings

- the CWTS Leiden Ranking. 


\section{Position of Dutch universities in international rankings}

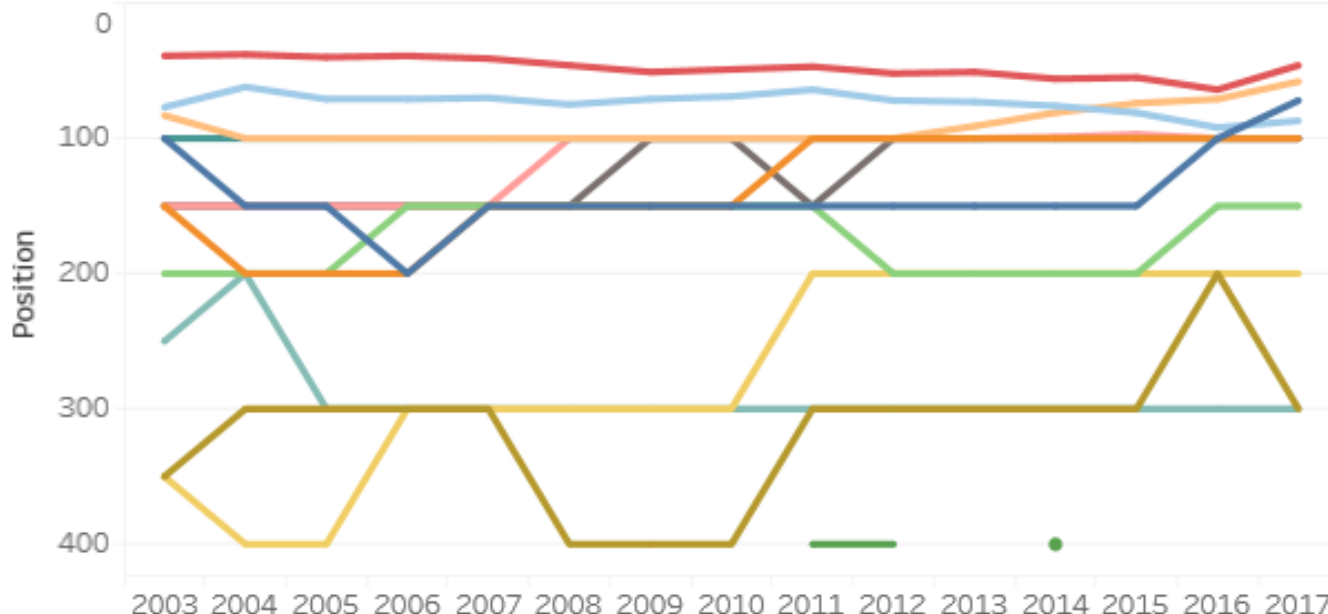

\begin{tabular}{|c|c|c|c|c|c|}
\hline Choose a year: & Choose a ut & niversity: & Choose & a ranking: & \\
\hline 2017 & (All) & 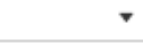 & Academ & ic Ranking o & orld Universities \\
\hline & ARWU & THE & QS & CWTS & Erasmus Univ. Rotterda... \\
\hline Erasmus Univ. Rotterdam & 73 & 72 & 147 & 75 & Leiden Univ. \\
\hline Leiden Univ. & 88 & 67 & 109 & 90 & Radboud Univ. \\
\hline Radboud Univ. & $101-150$ & 122 & 204 & 88 & Rijksuniv. Groningen \\
\hline Rijksuniv. Groningen & 59 & 83 & 113 & 147 & Tilburg University \\
\hline TU Delft & $151-200$ & 63 & 54 & 66 & TU Delft \\
\hline TU Eindhoven & $301-400$ & 141 & 104 & 133 & TU Eindhoven \\
\hline Tilburg University & & 195 & 357 & 296 & Univ. Maastricht \\
\hline Univ. Maastricht & $201-300$ & 103 & 200 & 134 & Univ. of Amsterdam \\
\hline & & & & 1034 & Univ. Twente \\
\hline Univ. Twente & $301-400$ & 179 & 179 & 180 & Univ. Utrecht \\
\hline Univ. Utrecht & 47 & 68 & 109 & 61 & VU Amsterdam \\
\hline Univ. of Amsterdam & $101-150$ & 59 & 58 & 64 & Wageningen Univ. \\
\hline VU Amsterdam & $101-150$ & 165 & 218 & 93 & \\
\hline Wageningen Univ. & $101-150$ & 64 & 124 & 84 & \\
\hline
\end{tabular}

\section{Source: VSNU}

According to the Dutch Rectors' Conference (VSNU) the Dutch universities are among the world's best 2\%. This positioning is exceptional, as the Dutch higher education system is an open access system; Dutch universities have no control over the students they admit. Furthermore, Dutch universities are all funded according to the same principles and only moderately resourced compared to universities in the US or the UK. By way of illustration: the net assets of, for example, Harvard University, are over eight times as high compared to the budget of all the Dutch universities combined. The budget per student (based on 2014 data) is shown below. 


\section{How much is spent per student? (Oocc Education at a Glance 2017)}

\section{Annual expenditure per student by tertiary education institutions} for all services (2014)

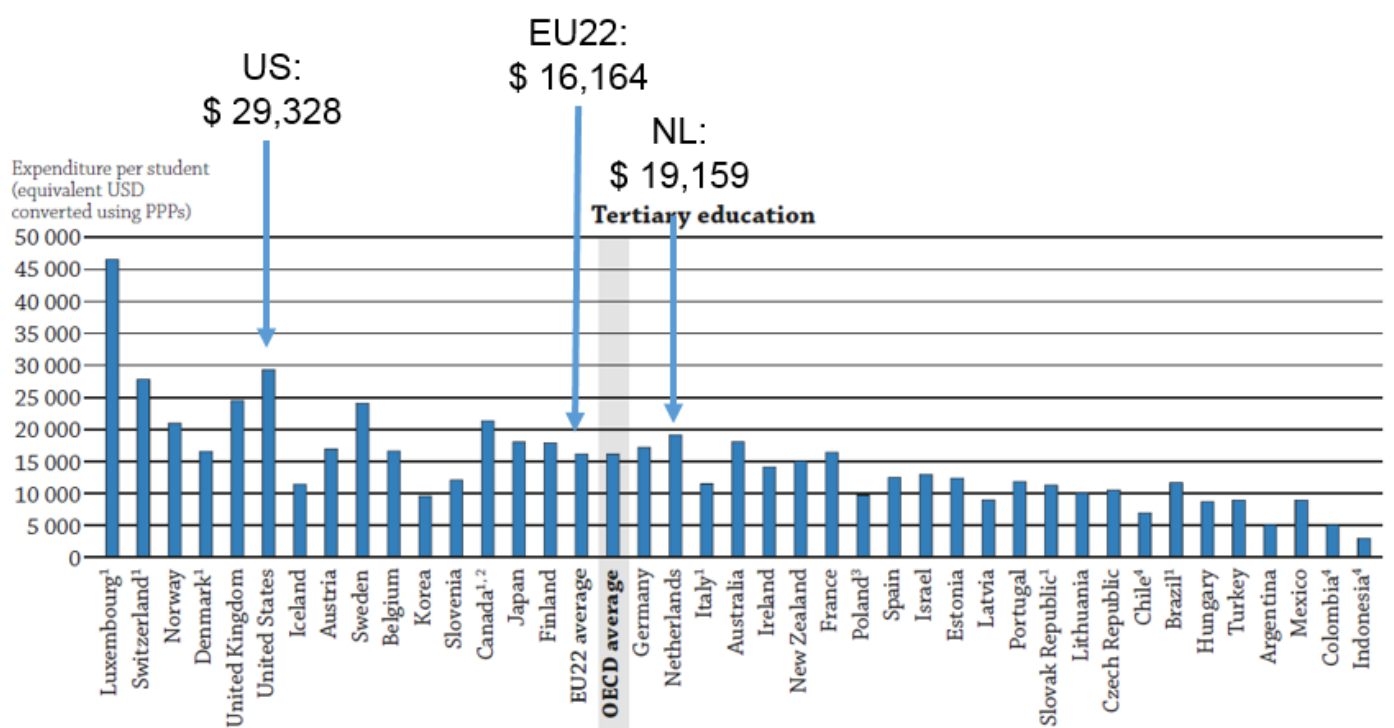

Expenditure on core, ancillary services and R\&D, in equivalent USD converted using PPPs, based on full-time equivalents (Indicator B 1.2)

Source: OECD (Education at a Glance 2017)

The quality of a country's research system can also be derived from the number of its universities included in the top 50 of higher education organisations that receive the most in terms of funding from the European Commission's Horizon 2020 programme (see next page). In terms of the 2015 grant beneficiaries, most of them were found in the United Kingdom (where 15 out of 50 were based), nine were based in Netherlands (see list below - names in bold) and five in Germany and in Sweden (EC, 2016). The Technical University of Delft holds position 5 (with over EUR 50 million in EU funding and 69 participations). Overall, less than $15 \%$ of the grant applications were funded in the first three years of Horizon2020. The Netherlands - together with Belgium and France - has an above-average success rate in obtaining funding on the basis of its grant applications. 


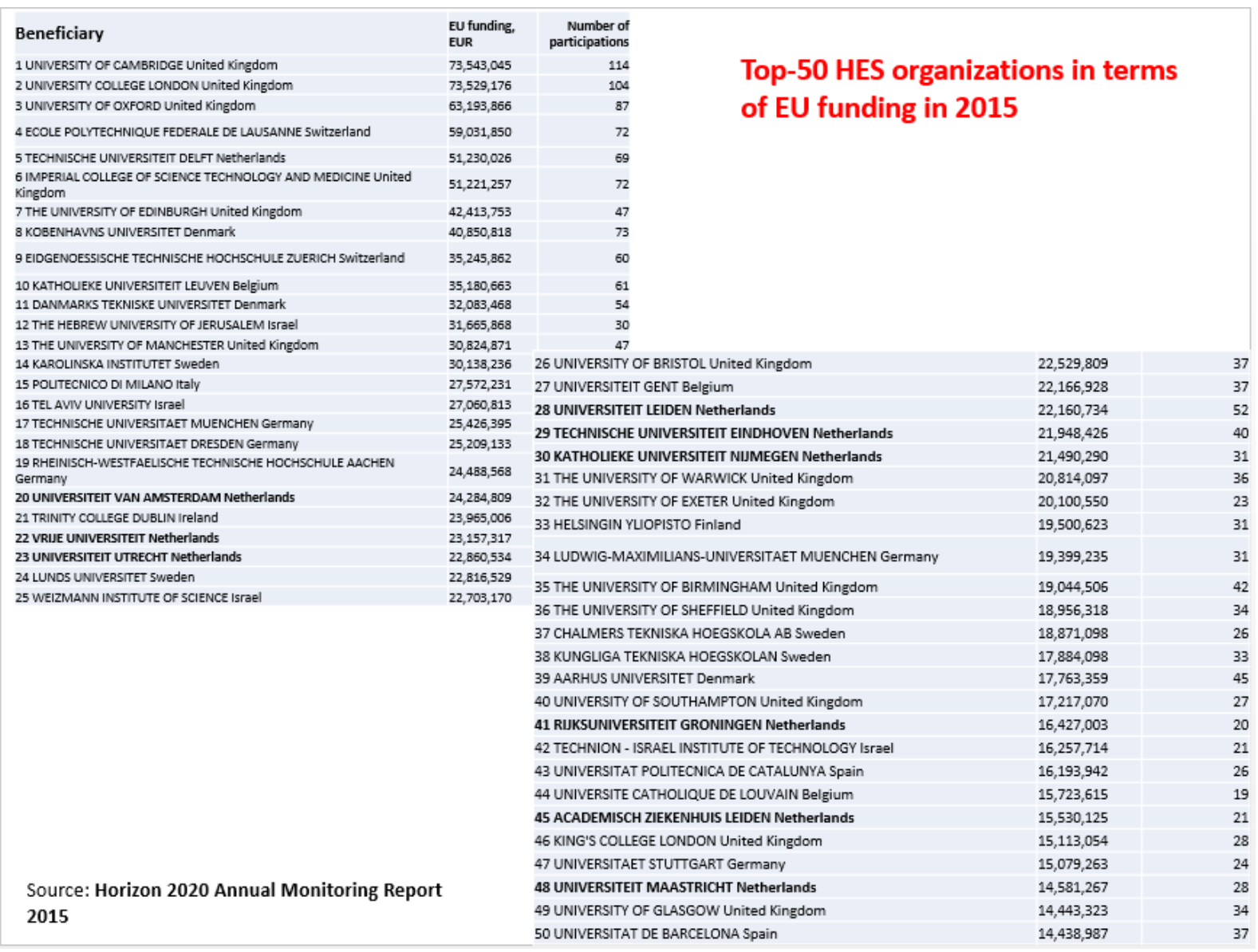

Source: European Commission Horizon 2020 Annual Monitoring Report 2015

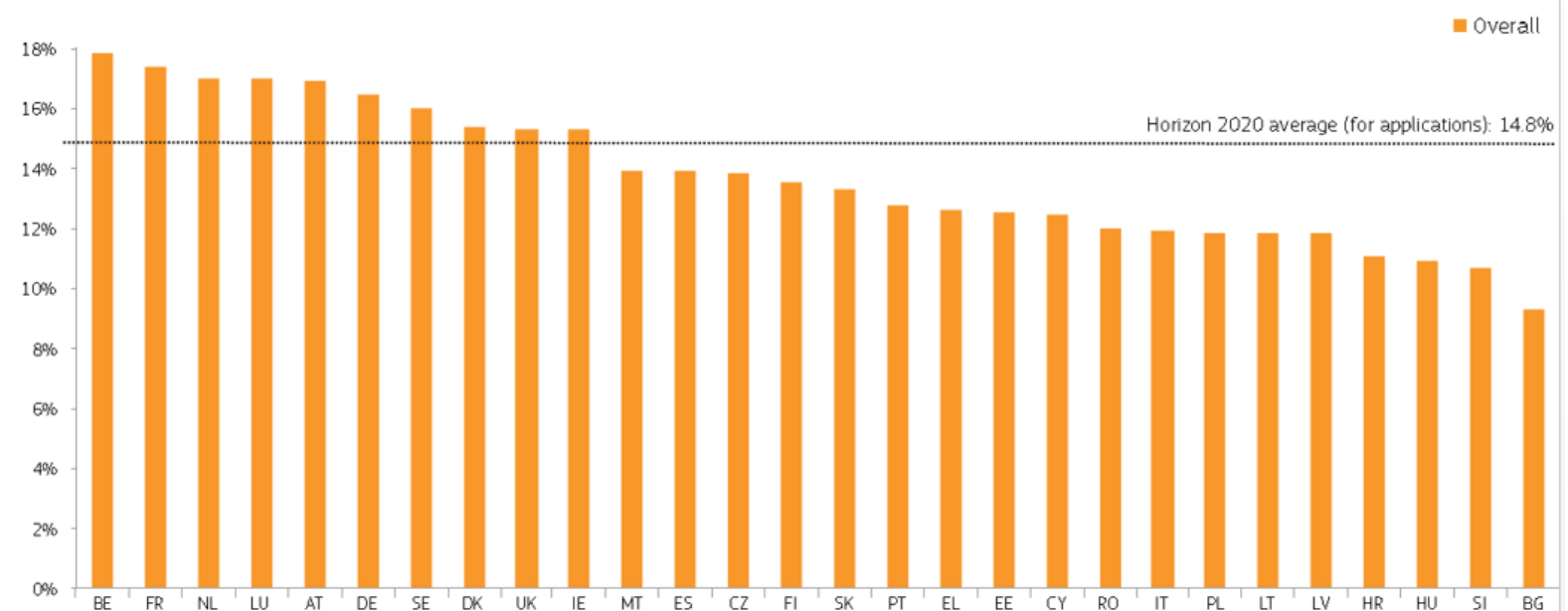

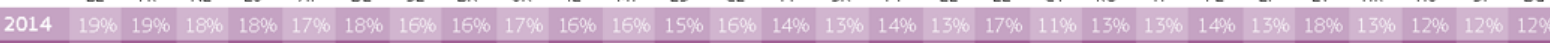

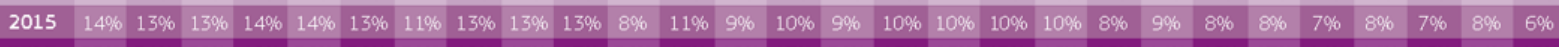

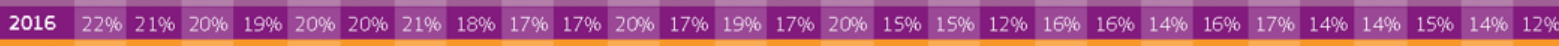

Source: European Commission (2017), Horizon 2020 in full swing - Three Years On - Key facts and figures 2014-2016 


\section{Key actors in the Dutch higher education system}

\subsection{The Dutch higher education system}

The higher education and research system in the Netherlands is a complex system, with many actors, relationships, funding mechanisms, policies and inter-relations. This section gives a description of the main actors in the system and their roles. The main policy actors in Research and Innovation (R\&I) are the Ministries of Education, Culture and Science (ECS; Dutch acronym: OCW) and Economic Affairs and Climate (EAC; Dutch acronym: EZK). ECS is responsible for science and education policies and the allocation of institutional funding to the higher education institutions. The main R\&I policy implementation bodies are the Netherlands Organisation for Scientific Research (NWO), the Royal Netherlands Academy of Arts and Sciences (KNAW), and the Netherlands Enterprise Agency (RVO). ECS and EAC share the responsibility for enterprise policy, which includes innovation policy.

The publicly funded higher education sector is binary in structure: On the one side there are 14 research universities (including an Open University) and four small denominational universities (e.g. theological universities). On the other side there are 37 universities of applied sciences (UAS; in Dutch: hogescholen). Over 63\% of students are in the UAS sector; the remainder in the research universities.

Access to higher education is - with some exceptions (e.g. medical programmes that have fixed number of new entrants) - open to all students that hold the required entrance qualifications implying there is little entrance selection. However, in the master's phase selection of students is possible. 
The Dutch research universities and their location

\section{4 universities \\ (plus four theological unis)}

enrolled

\section{0,000 students}

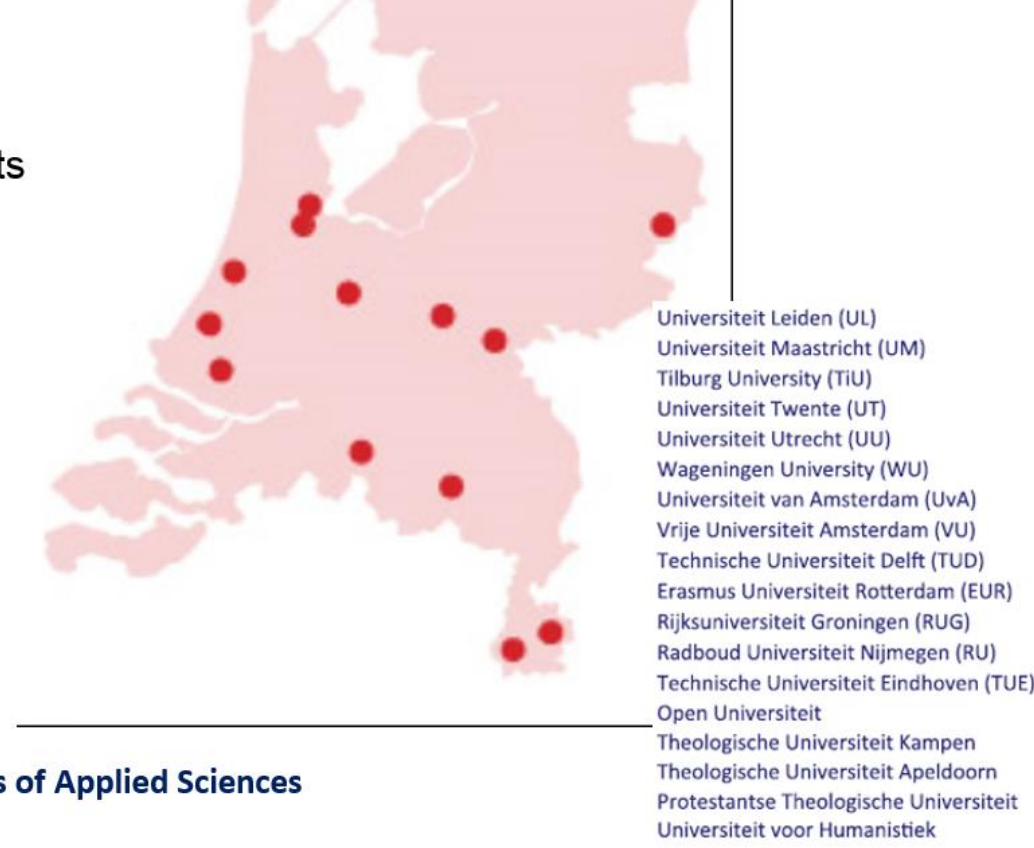


TU/e Technische Universiteit Eindhoven University of Technology

\section{UNIVERSITY OF TWENTE.}
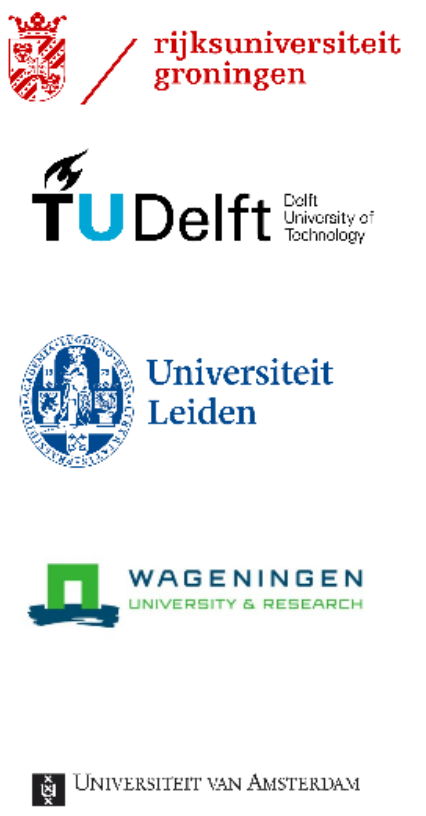

Maastricht University
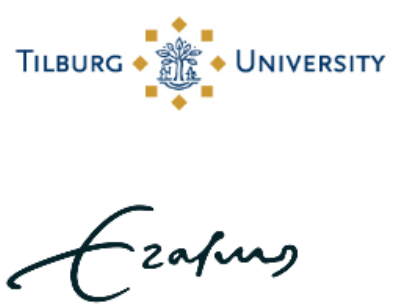

Silly Universiteit Utrecht

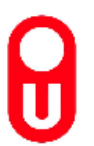

See: https://www.vsnu.nl/nl NL/Universiteiten.html

The research universities and the UASs are governed by the same law, the Higher Education and Research Act of 1993 (WHW). The WHW Act governs the quality of the publicly funded institutions, planning and budgeting, personnel, education, registration, teaching, examinations and doctoral studies, requirements for preliminary education and admission, students and external student auditors, the legal protection of students and external student auditors, and the administration and the structure of the various institutions. The Act extends also to the university hospitals (the University Medical Centres these are independent entities, but each them is closely affiliated to a university) and the Royal Netherlands Academy of Arts and Sciences (KNAW). The Act also provides the accountability frameworks, for instance with respect to the annual reporting and audits by the institutions. 
The Higher Education and Research Act, includes the following statement concerning universities:

Universities have the task of providing academic education and performing scientific research.

They shall in any case provide initial training in higher education, perform scientific research, provide training for scientific researchers or technological designers and ensure knowledge transfer to the benefit of society.

The UAS institutions provide professional higher education. They perform design and development activities and research aimed at professional practice. They provide bachelor's programmes and, where appropriate, master's programmes. They provide knowledge for the benefit of society and contribute to the development of the professions at which their education is directed.

The research universities focus on the independent practice of research-oriented work in an academic or professional setting. They train students in academic study and research, although many study programmes also have a professional component. In terms of research, the universities are expected to strive for excellence and relevance. First, to strengthen the quality of their research groups, concentrating their research on areas of strength, and, secondly, to valorise their research, i.e. to create economic, social and cultural value from their research. The latter includes taking initiatives to make research contribute to stimulating innovation in economically important areas.

The research universities comprise three universities of technology (Delft/TUD, Eindhoven/TU/e, Twente/UT), a university focusing on life sciences and agriculture (Wageningen/WUR), six comprehensive universities (Leiden/UL, Amsterdam/UvA, Amsterdam/VUA, Utrecht/UU, Nijmegen/RU, Groningen/RUG) and three more specialised universities (Rotterdam/EUR, Maastricht/UM, Tilburg/TiU). Eight of these universities are 
associated with an Academic Medical Centre. Taken together, in 2015 the thirteen universities offer 400 bachelor degree programmes and 800 master's programmes.

Universities of Applied Sciences (UASs) are preparing students directly for specific professions and careers. Their study programmes focus on the practical application of knowledge. The UASs award mostly bachelor's degrees, but they have recently also started to award associate degrees and master's degrees. The universities of applied sciences offer some 850 bachelorlevel programmes, 145 master's programmes and 90 associate degree programmes.

The universities of applied sciences are very diversified, with some of them offering a wide range of programmes and playing an important role as providers of higher professional education for their region. Others are more specialized (such as schools in the area of arts, and colleges for teacher training, agricultural studies, hotel management and tourism), with some (in particular the art schools) having a wider (including international) catchment area. Since 2006, the universities of applied sciences are offering two-year associate degree programmes to bridge the gap between post-secondary vocational education and higher education. These days, UASs are encouraged to specialise in their own research themes, strengthen their research infrastructure, and link up with other HEIs and the private sector. The research in the UAS sector is known as practice-oriented research or design \& development, highlighting that the UAS sector carries out its own type of research.

Later on in this document we will describe the funding of universities. 
2.2 The bigger picture: key actors in the higher education and research system

The picture below shows the main actors in the Dutch higher education and research system. It distinguishes four levels (national/international; ministries; intermediary organisations; higher education and research institutions) and a wide array of advisory councils/bodies/representative organisations. The connecting lines in the picture refer to funding flows, that is the grants, subsidies and other resource flows.

\section{Overview of the main actors in the Dutch higher education and research system}

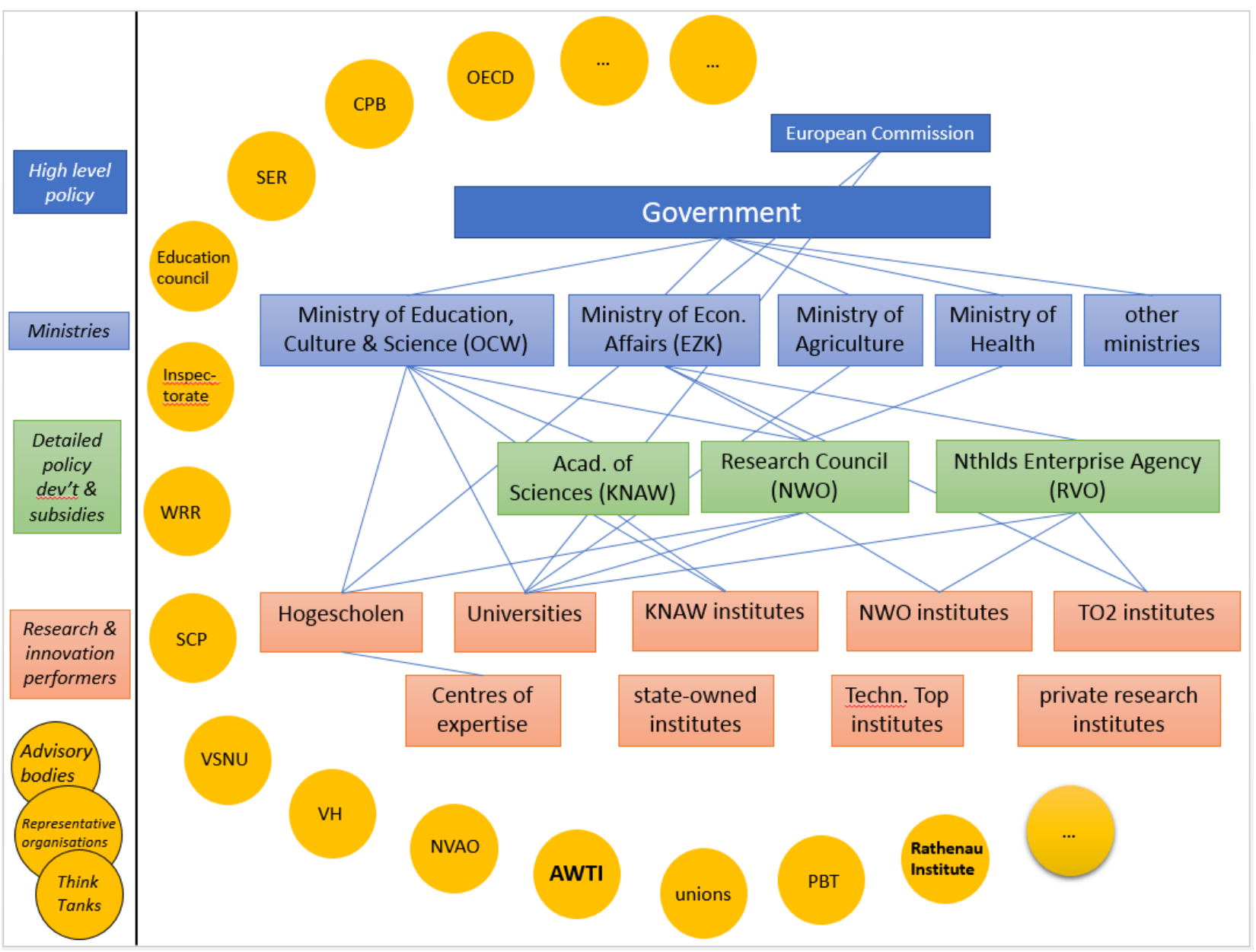

Source: CHEPS

Quality control of the higher education programmes is carried out by the Accreditation

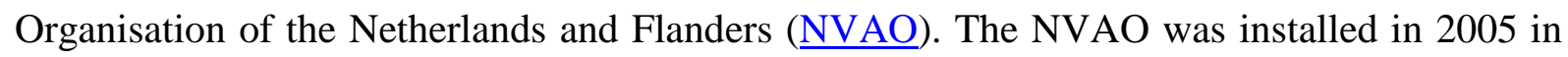


order to fulfil tasks of quality assessment, evaluation and control. The Inspectorate of Education (in Dutch: Onderwijsinspectie) is responsible for the inspection and review of educational institutions. It reports about the developments and key themes in Dutch education, including higher education. The Education Council (in Dutch: Onderwijsraad) is an independent governmental advisory body which advises the Minister of Education, the Minister of Economic Affairs, Parliament and local authorities on issues related to education (at all levels from pre-primary to higher education).

The universities defend their common interests through their representative organisation (say, rectors' conference), the Association of Universities in the Netherlands (VSNU). The VSNU is one of the partners in the national policy network with respect to higher education and research. Universities of Applied Sciences have organized themselves in the Netherlands Association of Universities of Applied Sciences (in Dutch: Vereniging Hogescholen). The VSNU and the Vereniging Hogescholen also function as employers' organisations on behalf of their member universities. They negotiate with the unions about collective labour agreements for the university and UAS sectors.

\subsection{Ministries}

At the level of the government the most important actors are the Ministry of Education, Culture and Science (OCW) and the Ministry of Economic Affairs (EZK). The Education Ministry has an overall responsibility for the governance of the higher education institutions and the public research organisations and research institutes in the system. The Ministry of Economic Affairs has the responsibility for innovation policy instruments and all matters concerning applied and industry oriented R\&D. The two ministries work together on areas such as the promotion of entrepreneurship and the strengthening of the links between education and the world of work. Another body responsible for managing and implementing policies in the area of innovation is the Netherlands Enterprise Agency 
(Rijksdienst voor Ondernemend Nederland - acronym: RVO.nl). This agency of the Ministry of Economic Affairs is primarily focusing on (innovation subsidies for) entrepreneurs, but it also provides information, training, and individual advice for universities on how to participate in the European Commission's Horizon 2020 programme for financing European research and innovation projects.

Once every four years the Education Ministry releases its strategic agenda, setting out the government's higher education policies for the future. The most recent strategic agenda (Ministry of Education, Culture and Science, 2015) was published in 2015 and primarily covers policies and spending plans related to education, leaving the ambitions and policies related to research to a separate policy document, also published regularly: the Science Budget ('Wetenschapsbudget'). The latest Science Budget was published in 2017 and was based on a white paper by the ministry, the Wetenschapsvisie 2025 (Science Vision 2025), that had been released in 2014. This Science Vision 2025 document included the government's future plans for academic research, based on an evaluation of the various science policies and funding streams in place.

Earlier this year (2018) the government produced more concrete plans on (extra) investments in research. The coalition agreement signed between the political parties that make up the current coalition government announced a range of proposals, including an ascending extra yearly investment in research of up to $€ 200$ million in fundamental research and another $€ 200$ 
million in applied research, as well as an incidental investment of $€ 100$ million in large technological institutes.

Home $>$ Ministries $>$ Ministry of Education, Culture and Science $>$

\section{Organisation}

The Ministry of Education, Culture and Science comprises a governing body and a number of executive services and inspectorates.

Political leadership is in the hands of the Minister of Education, Culture and Science Ingrid van Engelshoven and Minister for Primary and Secondary Education and Media Arie Slob. A management team is responsible for the civil leadership of the Ministry, with the Secretary General at its head.

- Minister of Education, Culture and Science

- Minister for Primary and Secondary Education and Media

- Secretary-General

- Inspector-General of Education (Inspectorate of Education)

- Inspectorate of Heritage

- Director-General of Primary and Secondary Education

- Director-General of Higher and Vocational Education, Science and Emancipation

\section{Civil leadership}

The Management Team for Education, Culture and Science (MT-OCW, Dutch abbreviation) forms the civil leadership of the Ministry. The MT-OCW is responsible for policy-making, which is then immediately implemented by other divisions of the Ministry. In addition, the team lends support to the Minister and State Secretary in governing the organisation and advises the Minister on matters of national policy. The Secretary-General is at the head of the MT-OCW, which also includes the Deputy Secretary-General, the four DirectorGenerals and the Inspector-General of Education.

\section{Secretary-General}

The Secretary-General is the Head of the MT-OCW. The SG leads all parts of the Ministry, including government services and inspectorates. The SG carries out his task in accordance with current political policy and is the first political adviser to the ministers.

The current Secretary-General is Mrs. M.J. (Marjan) Hammersma (drs.). 


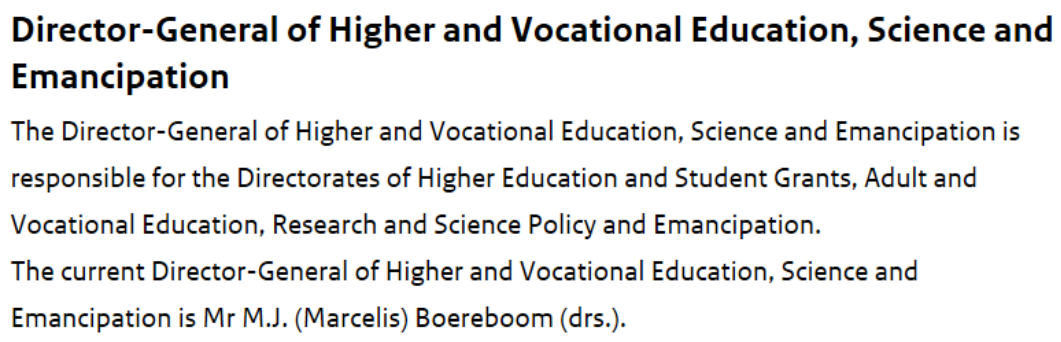

See: https://www.government.nl/ministries/ministry-of-education-culture-and-science/organisation

\subsection{Other organisations}

Decisions on distributing science budgets and on implementing the research and innovation policies are mediated through various intermediary bodies. The most important is the Netherlands Organisation for Scientific Research (NWO), the Dutch research council, that acts as the most important intermediate funding organisation in the field of fundamental and strategic research. NWO awards competitive research grants to researchers and research teams. Apart from playing a role as a funding organisation, NWO owns nine research institutes in the fields of astronomy, mathematics, computer science, physics, history, sea research, law, criminality and space research.

NWO recently underwent a major restructuring. From 2017 onwards it has aggregated the nine scientific areas covering four scientific domains (i.e. exact and natural sciences, social sciences \& humanities, applied sciences and engineering, medical sciences) that each have their own governance structure under the umbrella of NWO. This also holds for the research institutes owned by NWO, that are in a separate organisation from 2017 onwards. NWO's Taskforce for Applied Research SIA awards grants to universities of applied sciences in order to encourage practice-oriented research.

NWO is an important source of funding for scientists exploring new ideas in all scientific disciplines. The primary instrument for this is the Open Competition. As part of this, the NWO 
Innovational Research Incentive Scheme awards competitive grants to scientific talent in different stages of their research career - the Veni, Vidi and Vici grants.

Through its Zwaartekracht (Gravitation) programme, NWO encourages excellent research in the Netherlands. The programme is for scientific consortia that have the potential to rank among the world's best in their field. The programme is a form of direct government research funding, meaning Gravitation subsidies are part of the first funding stream (see below).

NWO has announced a range of measures to reduce the current high pressure on scientists to apply for research grants. It will more closely collaborate with universities, work on the timing of its calls, rethink its assessment criteria and NWO will consider alternative forms of research assessment. NWO will start an experiment with the sand pit model for a limited number of grants. In this model, a committee holds talks with a number of consortia to bring together the best ideas, expertise and facilities.

The latest round of the Gravitation programme was held in 2016. Approximately $€ 110$ million was allocated to six consortia ( $€ 18,8 \mathrm{~m}$ for each consortium) for a period of ten years. Two out of the six consortia (focusing on Quantum Software, resp. Anchoring Innovation) are led by scientists from the University of Leiden. In previous years, the University of Amsterdam managed to acquire a Gravitation grant (for its Networks consortium).

The Gravitation subsidies replaced the grants for a highly selective number (six) of top research schools. The top research schools are still in place. One of them is located at the University of Amsterdam (NOVA, focusing on astrophysics). 
The gravitation grants are one of the instruments put in place to achieve scale and focus in the Dutch research landscape. The grants are meant to lead to centres of expertise in research that have a substantial scale (or mass). Through its grants, NWO is supporting capability (the base of the pyramid) as well as scale and focus. An example of grants aimed at the base of the pyramid is the Innovational research incentive scheme.

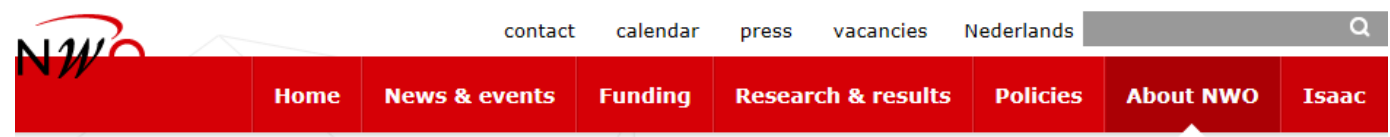

>Mission and vision
> Strategy
' What does NWO do?
'Key areas
> Organisation
> New NWO
> Working at NWO
>Media

About NWO

See: https://www.nwo.nl/en

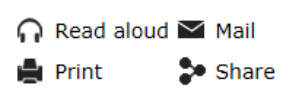

Mission and vision

NWO is committed to a strong science system in the Netherlands, in the belief that scientific research contributes to our prosperity and wellbeing.

> Mission and vision

\section{Strategy}

In the period 2015-2018, NWO maintains the broad outline of its policies and puts a new emphasis on cooperation and communication between science and society.

> Strategy

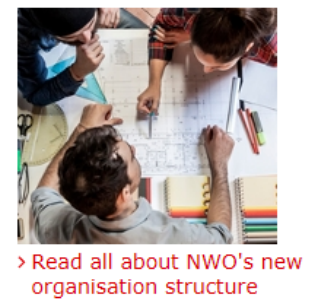

\section{Key areas}

NWO focuses on five key areas of interest: Curiosity-drive research and talent, Thematic research and PPP, International collaboration, Large research facilities and National research institutes.

$>$ Key areas

The Royal Netherlands Academy of Arts and Sciences (in Dutch: KNAW) is an independent council advising the government on issues of science policy, especially related to the field of basic research (e.g. codes of conduct, quality assurance, and research schools). The Academy houses three societies: the Learned Society, which has more than 500 members; The Young Academy, with fifty members; and the Society of Arts, also with fifty members. The KNAW is responsible for 15 research institutes that are 
active in the life sciences, humanities and social sciences. These are research institutes comparable to those of NWO. It is also awarding scientific prizes and scholarships to researchers.

In its Strategic Agenda the Academy has set itself the goal of reinforcing the connections between scientific disciplines and science organisations, between science and society, and, internally, between its three societies and 15 research institutes.

An important role for the KNAW is to help set out the criteria that are used nationally to assess the quality of academic research. The methods used to assess research conducted at Dutch universities and NWO and Academy institutes every six years are published in its $\underline{\text { Standard }}$

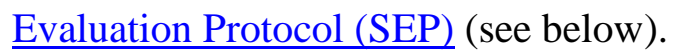

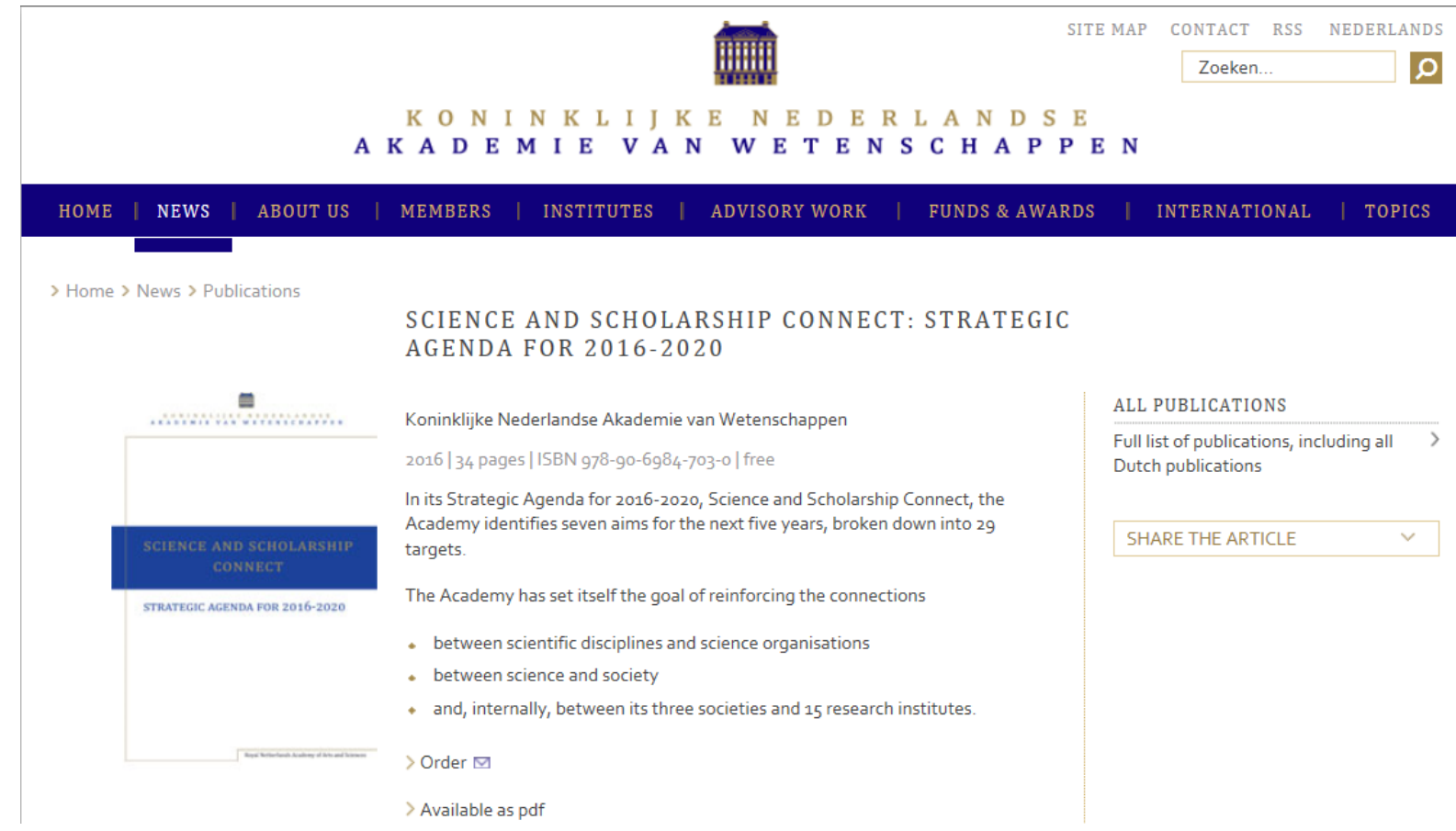

See: https://knaw.nl/en/about-us

A large number of research schools have been created by universities from the early 1990s onwards. These schools are places where universities work together to offer structured training programmes to primarily - PhD candidates that work in a particular disciplinary field. The Royal Academy of Sciences 
(KNAW) is responsible for the recognition (i.e. accreditation) of the research schools. Today, more than 60 research schools exist - a few of them have been awarded the status of Top research school and receive additional public funding. Apart from research schools, universities also have graduate schools, where $\mathrm{PhD}$ programmes and programmes for students doing a research Master's degree are concentrated.

The Advisory Council for Science, Technology and Innovation (AWTI), an independent body, advises the government and parliament on policies relating to scientific research, technology development and innovation, with several yearly thematic reports. The AWTI also acts as a council the government can consult. Several other bodies are of relevance for science policy advice as well, such as the Scientific Council for Government Policy (WRR) and the Rathenau Institute.

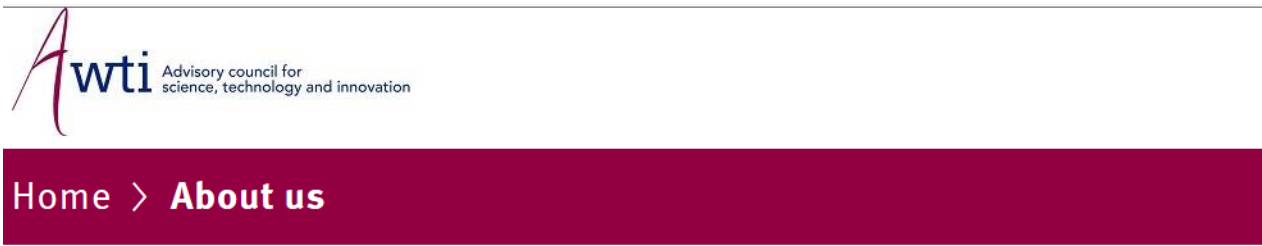

The AWTI advises the Government and the Parliament on policies related to scientific research, technological developments and innovation. Knowledge, research and innovation are important for all policy areas. In spite of this, the AWTI mainly relates to the areas dominated by the minister of Education, Culture and Science (science policy) and Economic Affairs (innovation policy).

> The Council

$>$ Staff

$>$ Work method

\section{Task}

The AWTI is a strategic advisory council, (as stipulated in 2014). The official task of the council consists of the following: 'The council will advise the government and the StateGeneral on national and international policies with respect tot science, technology and innovation, with special attention for the connection between science, technology and innovation and its impact on economy and society'. The AWTI advises on policy 


\section{The council}

The advisory council consists of a maximum of 10 members, each originating from different sectors of society, such as research institutes and trade and industry. The members do not represent any special interests. Here you can find more information about the members.

See: https://english.awti.nl/about-us

The Rathenau Institute is a government research institute that stimulates public and political opinion forming on social aspects of science and technology. It carries out research and organises debates relating to science, innovation and new technologies.

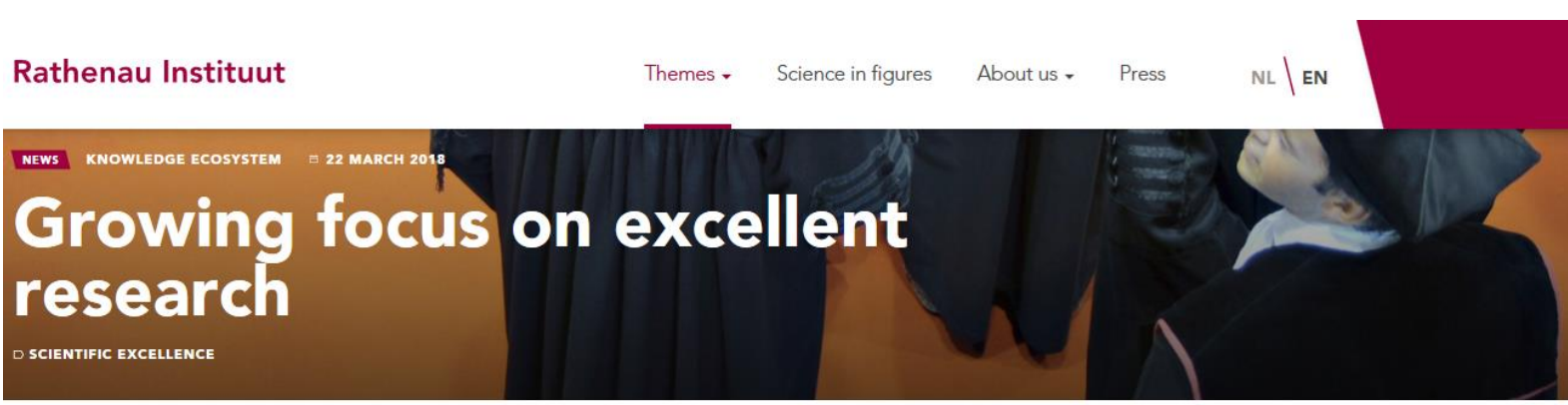

Home $\cdot$ Knowledge ecosystem · Growing focus on excellent research

Grants and other funding instruments for excellent research are having a growing impact on science.

Since the early 1990 s, the Dutch government has honoured excellent researchers by awarding them grants and prizes. It has focused these efforts primarily on individual researchers who do trailblazing basic research. A large proportion of the budget available to NWO and the EU to fund research goes to excellent research. NWO's Talent Scheme, the ERC grants and other funding instruments are having a growing impact on science in this way. That is one of the conclusions of our new analysis.

The budget for excellent research has more than doubled in the past ten years, from $€ 160$ million in 2006 to more than $€ 370$ million in 2016. This money goes to a small group of researchers who work at Dutch universities, university hospitals and other research institutes. At any given time, about $5 \%$ of all researchers in the Netherlands have an excellence grant. This represents $40 \%$ of the public research revenues acquired in competition by universities and university hospitals from the EU and NWO. Researchers at non-specialist universities receive the most excellence grants, relatively speaking.

The analysis shows that the original objectives of the government's excellence policy are being achieved. The concentration of funding gives a relatively small group of researchers the opportunity to do trailblazing research. That concentration has continued because a growing number of grants are awarded to previous laureates.

A very useful document produced by the Rathenau Institute is The Balance of Science. The Balance of Science 2016 decomposes the three key ambitions formulated by the government in its Science Vision 2025 into more specific policy goals and ultimately translates these into measurable indicators. 
For instance, the (first) ambition 'Dutch science is world class' is elaborated in four policy objectives:

1. Dutch research is a plateau-with-peaks.

2. Dutch science is well embedded internationally.

3. There is sufficient space for free and unbound research.

4. Scientists have access to state-of-the-art research facilities

The ambition 'Science with maximum impact' has been elaborated into the goals of:

1. Contributes to societal challenges.

2. Contributes to innovative strength.

3. Contributes to human capital.

4. Widely accessible to society.

5. Enjoy broad trust and visibility in society.

The ambition 'Breeding ground for talent' has been elaborated in the baseline measurement in the following policy objectives:

1. Attract and train talent.

2. Give talent more space.

3. Expand talent more broadly.

For each of these goals, the Rathenau Institute produced indicators as a baseline measurement. Also the Association of Universities in the Netherlands (VSNU) tends to play a key role in debates about how to organize science policy. The Social and Economic Council of the Netherlands (SER) advices on issues related to for instance the labour market. The Netherlands Bureau for Economic Policy Analysis (CPB) and the Social and Cultural Planning Office (SCP) also produce reports on higher education and research matters.

In terms of research performers beyond universities and UASs, we already mentioned the institutes operated by the Academy of Sciences (KNAW) and the Research Council (NWO). Apart from these, one should also mention the other publicly supported applied research 
organisations. These are known as the large technological institutes, collaborating in the $\underline{\mathrm{TO} 2}$ federation. TO2 comprises the Netherlands Organisation for Applied Scientific Research (TNO), Deltares (applied research in the field of water and subsurface), the Energy Research Centre of the Netherlands (ECN), the National Aerospace Laboratory (NLR), and the Maritime Research Institute Netherlands (MARIN). The TO2 organisations conduct applied research and related activities, such as supporting industry and government in specific fields. The TO2 institutes receive basic financing from the government but a large part of their budgets derives from specific ministry allocations, European research funds and contract research carried out for industry. Their main activity is (applied) research and development - encouraging the innovative capacity of the Dutch economy.

\section{Funding for academic research}

The policy framework for the Dutch academic research enterprise revolves very much around funding and quality assurance mechanisms. In the most recent decade, a large emphasis was placed on policies that stimulate the transfer of knowledge from academia to industry, in particular through the promotion of public-private partnerships.

Public financing of research is an important mechanism by means of which the Dutch government tries to achieve the main research policy goals. We will mainly be concerned here with the funding of university research, since universities are the centrepiece of the Dutch academic research enterprise. The funding that universities receive for research is to be understood from the context of their overall funding framework, which is pictured in the figure below. The figure presents the main funding flows to the 13 publicly funded Dutch universities (leaving out the Open University). 


\section{Funding flows in higher education}

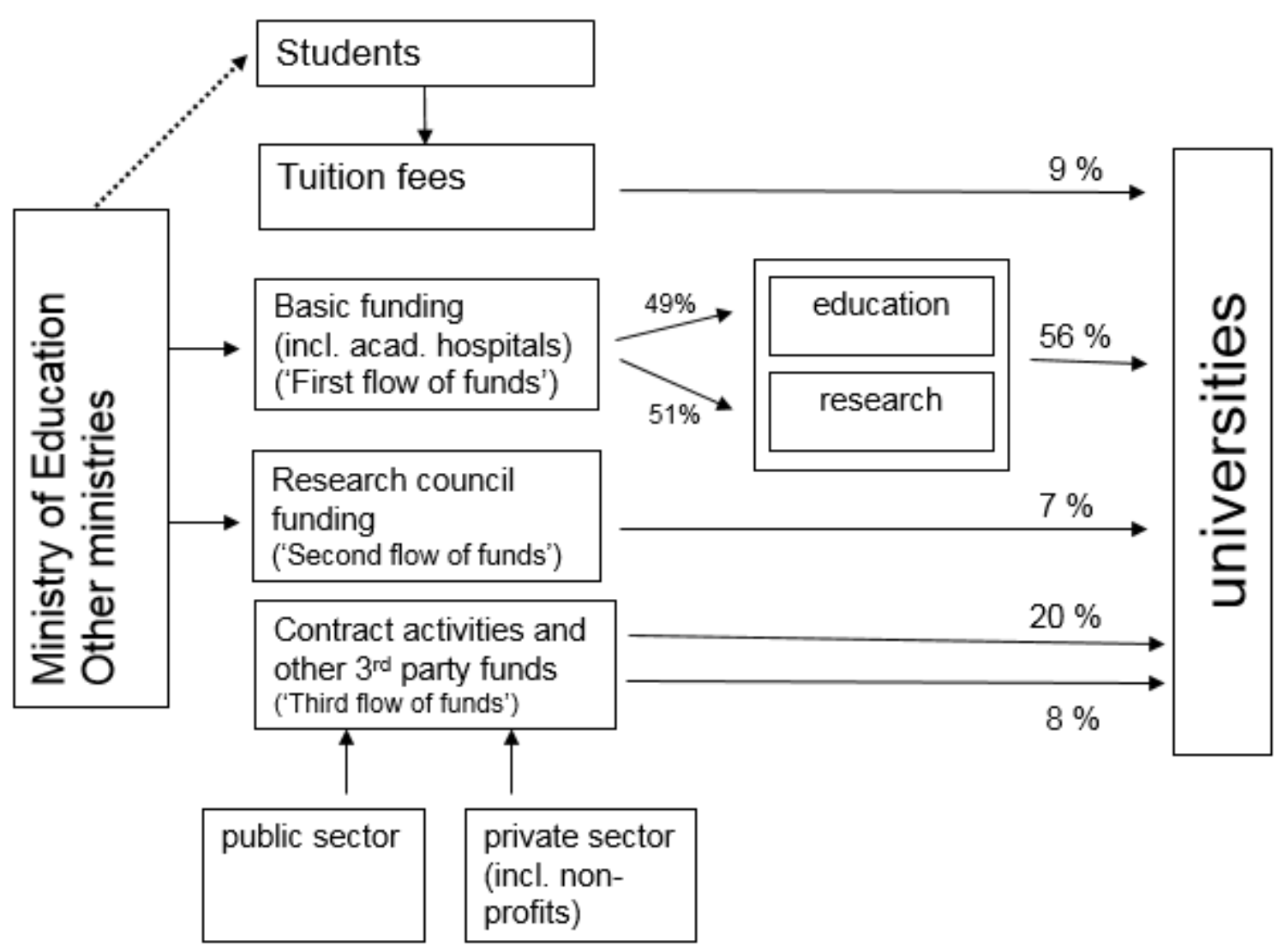

Source: CHEPS

Research universities and universities of applied sciences (UASs) are funded through the following sources (say flows) of funding:

- Tuition fees paid by students;

- Basic funding in the shape of a core grant provided by the ministry: the first flow of funds;

- Competitive project- and programme-based research funding, provided by the research council (NWO) or the Academy of Sciences (KNAW): the second flow of funds;

- Project-based funding for education and research carried out for public and private clients: the third flow of funds.

Tuition fees are to be paid by all students. If students are studying full-time and they are from the 
European Union, the European Economic Area, or Switzerland, they pay a fee that is equal across all institutions and programmes. The level of the fee is set by the ministry; in 2017 this is slightly over EUR 2000.

The core grant (the first flow of funds) is the largest source of revenue: it provides the funds that enable the universities to carry out their education and research tasks (including the education and research in University Medical Centres). Its size in 2016 was over EUR 3,6 billion for the research universities. The Ministry provides the core grant as a lump sum. This amount consists of budget components for respectively education and research, but the institutions have large degrees of freedom on the distribution of these resources.

For research universities the core funds for education are very much formula-based. Currently, the formula funds for education partly (roughly for two-thirds) depend on the sum of student enrolments and Bachelor's and Master's degrees. For the formula, only enrolments within the normative time to degree (in the research universities: 3 years for a bachelor; for a master's 1 , 2 or 3 years, depending on the programme) are taken into account. Enrolments and degrees are weighted by three different funding rates: low, high and top. The low rate of 1 for studies in the field of economy, law, social sciences \& humanities and language \& culture; the high rate of 1.5 for education, agriculture, technology and health, and the top rate of 3 for medicine-related programmes. Another part (one third) of the formula funds for education is provided in the shape of largely fixed sums per university. The same approach is used for universities of applied sciences (with the proviso that bachelor's programmes last 4 years and master's normally 1 year) with the rates being $1,1.28$ and 1.5 respectively. 
These days, some $20 \%$ of the research component in the universities' core budget is based on the number of $\mathrm{PhD}$ degrees, applying a fixed rate per $\mathrm{PhD}$ degree awarded. A large part of the research allocation ( $65 \%$ on average per university) is distributed primarily on the basis of fixed (historically-based) allocations per university, including subsidies for a selected number of research schools (i.e. the six top research schools). The remainder of the core grant for research $(15 \%)$ is based on the number of degrees awarded to students.

The core grant is intended to support the teaching and research mission of the universities. What is important to note here is that there is no separate funding stream for valorisation; resources for implementing third mission activities are to be found in the institutions' lump sum. However, there are various dedicated funds and subsidies for valorisation. Valorisation is increasingly stressed by the research council (NWO), playing a role as a criterion in its awarding of research grants. For instance, NWO's Innovational Research Incentive Scheme (i.e. its Veni, Vidi, Vici scheme), invites applicants for research grants to pay attention to valorisation.

A third revenue source for universities (amounting to about a quarter of the revenues) consists of competitive research funds, distributed by intermediary public organisations (especially the research council NWO), and other competitive funds. Part of the NWO budget is dedicated to support public-private partnerships in research - a policy known as the Top Sector strategy (see below). Grants from European research programmes, e.g. the European Research Council, are part of third party funds. Third party funds also include fees from contract teaching and from students doing non-degree programmes. In terms of contract research income, the universities are very active in generating research subsidies linked to encouraging public-private partnerships in research consortia. An important revenue source related to the latter was the Economic Reinforcement Fund (Fonds Economische Structuurversterking; FES). Below, we 
will describe the Top Sector policy that was introduced in 2011 and has similar objectives as the FES fund.

An independent Review Committee was created by the Education ministry in 2011 to oversee the performance agreements signed in 2012 for the period 2013-2016. The agreements were between the Education Ministry and each individual higher education institution. This Review Committee was in place from 2012 through 2016. The performance agreements were the result of the Dutch national policy for research universities and universities of applied sciences to work on the priorities of:

1. improving the quality of education and the success rate of students;

2. enhancing the differentiation within and between higher education institutions, encouraging them to exhibit more clear institutional profiles and

3. strengthening valorisation (i.e. knowledge dissemination, commercialization, promoting entrepreneurship) by universities and UASs. For the period 2013-2016, 7\% of the universities' grant for education (some EUR 130 million for the research universities) was tied to performance agreements.

In 2017, the Review Committee produced its final system report (Review Committee, 2017). In this report it also presented some (mildly positive) lessons from the performance agreements experiment.

Now that the performance agreements have come to an end, the current minister of Education recently decided on its follow-up: a system of quality agreements. The quality agreements only concern educational quality and are no longer about research and valorisation. Compared to the previous performance agreements, there are mild financial consequences attached to the quality agreements and less steering by the government in the process. 


\section{Quality assessment of research}

With respect to assuring the quality of research, we should mention that the Netherlands has a long tradition of assessing the quality of research. Since 1993, external peer committees have judged fundamental research taking place in the universities along the four dimensions of quality. These were (1) productivity (i.e. number of publications per academic), (2) quality of (publication) output, (3) societal relevance and (4) long-term viability of the research group. All of a department's research (in as far as this is organised in research programmes ) is judged on a five-point scale. The reviews are organized under the auspices of the universities' umbrella organisation (VSNU), based on an agreed protocol, the Standard Evaluation Protocol (SEP).

The SEP was revised a few years ago (KNAW, 2014). The revision of the SEP protocol was agreed between the Academy of Sciences, NWO and the Association of Universities in the Netherlands (VSNU). All research conducted between 2015 and 2021 in academic departments of research universities and the research institutes is assessed in accordance with this protocol. External assessment committees (peers) conduct these assessments for each unit or institute once every six years (not all at once, but on a rolling schedule). The assessment committee bases its judgement on three assessment criteria: research quality, relevance to society, and viability (the extent to which the unit is equipped for the future). In its evaluation report, the assessment committee offers that opinion both in text (qualitative) and in categories (quantitative, using categories 1 to 4). The four possible categories are "excellent", "very good", "good" and "unsatisfactory". The committee also makes recommendations for the future.

Unlike the previous protocol, the current SEP does not anymore evaluate the productivity (i.e. research volume) of a unit - and nowadays primarily focuses on quality, relevance and sustainability. The peer review panel expresses its judgement in terms of four scoring categories: 'excellent', 'very good', 'good', and 'unsatisfactory'. The university or research 
institute decides how the unit will follow up on the external assessment committee's evaluation results and recommendations. There is no direct connection between the outcome of the quality assessment and the size of the public grant received by the university for research, but the university administration can (and does) take the reviewers' judgement into account in its internal policy-making.

\section{Valorisation; Top Sectors Policy}

Societal relevance (valorisation) has long been included as a criterion in the Standard Evaluation Protocol SEP. It relates to contributions made to specific economic, social or cultural audiences, as expressed through contract research, advisory reports for policy-makers or contributions to public debate. The SEP intentionally avoids including an exhaustive list of valorisation indicators. The SEP also requests a narrative description of the societal relevance (i.e. impact) of the research in question. Policies for encouraging valorisation and entrepreneurship in higher education were implanted in light of the conviction that the Netherlands, despite its excellent performance in science, was lagging behind in terms of using its research output for strengthening innovation and the creation of jobs. This phenomenon was also known as the knowledge paradox (excellent scientific research but a low degree of utilization by business firms).

In the 2004 Science Budget, the government announced that universities also were to fulfil a third mission, next to their education and research missions. This third mission relates to the transfer of knowledge for the benefit of society and is also known as valorisation. From 2005 onwards, higher education institutions (universities and UASs) were to address valorisation in their strategic plans and to specify their activities and results in fulfilling this mission. One should stress that universities and UAS institutions already practiced valorisation before that 
year, but that knowledge exchange now formally is part of an institution's mission. The definition of valorisation that was adopted from 2009 onwards was (VSNU, 2013):

Valorisation is the process of creating value from knowledge by making knowledge suitable and/or available for economic and/or societal use and translating that knowledge it into competitive products, services, processes and entrepreneurial activity.

Most research universities have established incubators and centres of technology transfer. The University of Twente began in 1984 with the encouragement of academic start-ups. Since then supporting academic start-ups has become commonplace in other universities as well. These efforts have led to an increase in new companies founded by (former) university students and employees. In quite a few higher education institutions, entrepreneurship is to some extent part of an academic's competence profile. Each university now has made valorisation a part of its human resources policy. Lecturers, researchers and $\mathrm{PhD}$ candidates can participate in courses and training sessions to enhance their knowledge and skills of entrepreneurship. In the UAS sector, the business community has started playing a bigger part in defining the content and organisation of entrepreneurial education.

The promotion of valorisation is part of the broader policies for strengthening innovation, most of which are the responsibility of the Ministry of Economic Affairs. As from 2010, the Ministry of Economic affairs is responsible for innovation policy in the Netherlands, whilst the Ministry of Education, Culture and Science remains responsible for education and research policy. The Netherlands Enterprise Agency (RVO) was created as a pivotal point for information concerning innovation and financing, networking and regulatory matters. RVO is the executive organisation for the national innovation subsidy schemes. Surely, the Ministry of Economic Affairs is specifically concerned with the business sector. Its main package for stimulating R\&D within companies is the $R \& D$ tax credit facility (WBSO), providing tax reductions on $R \& D$ labour costs and other R\&D expenditures. 
One programme aimed at valorisation was mentioned earlier in this note: the Economic Reinforcement Fund (Fonds Economische Structuurversterking; FES). The income from this fund came from the exploitation of the large natural gas reserves owned by the Netherlands. The FES fund was abolished in 2010. The FES fund was a government investment programme set up in the 1990s, awarding competitive funds to strengthen the research infrastructure of the Netherlands. The programme supported relatively large project subsidies to consortia consisting of universities, private companies, research institutes, and other public organisations. FES funding also demanded private contributions from industry partners. The bulk of the funds was allocated to research universities. The fund started to function in the 1990s and has known a few rounds.

The FES fund was an example of a scheme intended to prioritise research, targeting it at research in a selected number of priority fields - areas of strategic interest for Dutch industry and society. Government felt that such a prioritization policy would contribute to the creation of 'focus and mass' in research, or so-called 'Peaks in the Delta'. The latter was the title of a government policy document that announced where the Ministry of Economic Affairs expected the future hot spots of technology-based economic activity to appear (Ministry of Economic Affairs, 2004).

In 2003 the Advisory Council for Science and Technology Policy (AWTI) had published an influential paper, Backing Winners (AWT, 2003) that discussed the strategy known as the "key areas approach". The key sectors approach was proposed by the first Innovation Platform, a temporary advisory body of the government that consisted of high-level representatives from academia, industry and the policy arena, chaired by the prime Minister. It was argued that the creation of focus and mass in the research capacity of selected key areas was necessary to 
maintain a strong and internationally competitive position. The key areas selected were: flowers and food; high-tech systems and materials; water; chemistry; creative industry; and pensions and insurance. They were chosen for their perceived strategic importance in terms of growth opportunities and relevance to societal challenges.

These policies illustrate that valorisation has received a lot of attention in recent decades. Several programmes and grants were developed and implemented. The Netherlands has a rich array of intermediary organisations that together provide space for consensus to emerge in a more "bottom-up" style (through the so-called Dutch "polder" process) than is typical in other OECD countries. There has been a great deal of change in Dutch innovation policy, in part as a result of the political and economic volatility of the last decade. At the same time, there does appear to be some continuity in the objectives pursued and in the sectors singled out for special attention. For example, the sectors chosen for the Top Sectors policy (see below), have clear antecedents in sectors prioritised by the Innovation Platform and the Peaks in the Delta programme.

Although the prioritization strategy is sometimes questioned, it still is very much alive today and in 2011 led to the Top Sector policy. In that year, the Netherlands started to focus its science and technology policies on nine key sectors. The sectors selected were: agro-food: horticulture and propagating stock; high-technology materials and systems; energy; logistics; creative industries; life sciences and health; chemicals; and water. The selection of these sectors was based on a combination of the intensity of the R\&D taking place in the sector and its export performance.

The linkages, ambitions and sectoral roadmaps have been formalised in so-called Top Consortia for Knowledge and Innovation (TKIs), of which some Top Sectors have more than one. The TKIs receive specifically designated funding from the research council (NWO) and are partly 
funded by private partners (in cash, or in kind). The Top Sector policy focuses at existing sectors and does not automatically provide the exploration of new niches in business and science, perhaps making it less dynamic. To address this risk, three cross-cutting themes were introduced: ICT, bio-based economy, and nanotechnology. Also, some Top Sector committees strive to explore new cross-sectoral opportunities and perspectives. Although the policy is consistent, SMEs are still underrepresented within the Top Sectors.

In 2010, the Science and Technology Platform (Platform Bèta Techniek; PBT) was given the task to support the creation of centres for technology and education: the Centres for Innovative Craftsmanship (in the vocational education sector) and the Centres of Expertise (in the UAS sector). The centres promote and stimulate innovation in professional education and support innovation within firms: students, teachers and UAS-researchers address real-world challenges, working towards innovative solutions that strengthen economic competitiveness. Some centres offer labs and other shared facilities to support SMEs in particular to organize their own R\&D.

In 2010 , the Valorisation programme was introduced by the ministries of Education and Economic Affairs. It is run by the Dutch Enterprise Agency (RVO) and its aim is to professionalise the knowledge transfer process in the Netherlands in general. A budget of EUR 63 million was available for supporting 13 projects carried out by regional consortia, grouped around one or more higher education institutions in a region and led by a research university. The programme intends to stimulate entrepreneurial education, screening and scouting of knowledge transfer opportunities, supporting IP applications, provide pre-seed funding and proof-of-concept funding, stimulate network creation and initiate other activities that contribute to knowledge exchange. For these activities quantified goals were set for the 
first four years. The idea is that the activities will continue even after the government support has come to a halt in 2018, when the Valorisation programme ends.

\section{Recent developments}

In this final section we will briefly describe some recent (i.e. up to mid-2018) policy initiatives. In 2014, the government published Science Vision 2015 - Choices for the Future (in Dutch: Wetenschapsvisie 2025). It presents a vision on how to ensure that science in the Netherlands maintains its excellent status internationally. The Science Vision specifies the Ministry's strategy for the funding of research and also addresses the role of the research council NWO in its financing of research. NWO is expected to explicitly take into account the valorisation records and plans of scientists when judging proposals for awarding research funding.

The Science Vision 2025 makes it clear that the government wants to maintain and strengthen the position of Dutch science. In this policy document three ambitions are formulated for 2025:

1. Dutch science is world-class.

2. Dutch science is connected to society and business, and has maximum impact.

3. Dutch science is a breeding ground for talent.

In its Science Vision, the government announced the release of a National Research Agenda, that was to identify promising challenges for science that arise from social and economic challenges. The National Research Agenda was drawn up by a knowledge coalition (Kenniscoalitie, 2015). This coalition consisted of the Dutch Research Council (NWO), the Association of Universities in the Netherlands (VSNU), the Royal Netherlands Academy of Arts and Sciences (KNAW), the institutes for applied research (TNO, TO2), the Netherlands Association of Universities of Applied Sciences, the Confederation of Netherlands Industry and Employers (VNO-NCW), the Royal Association SME Netherlands and the Confederation of Academic Medical centres (NFU). A large number of 
stakeholders, ranging from individuals and representatives from science to people from the business community and civil society organisations were invited to send in their suggestions for scientific issues and questions to be included in this agenda. The questions were inspired by scientific curiosity as well as a wish to address big societal challenges and economic opportunities. In total 11,700 questions were submitted. The questions were condensed into themes and at the launch of the National Research Agenda (in November 2015) a total of 140 broad scientific questions had been identified. The government has stated its goal to make the Agenda a leading instrument in the award of funds for science. It should be an instrument supporting scientific breakthroughs.

After the release of the National Research Agenda, the various parties in the knowledge coalition took the agenda as the starting point for defining a number of "routes" ( 25 in total were defined) and suggested ways in which these routes could be shaped to advance not just science in general but the Netherlands in particular. The routes illustrate the relationships between natural sciences and social sciences and between academia and society in addressing complex social issues. This is expected to lead to a number of thematic priorities for science. Some of these were suggested by the partners in the Knowledge Coalition, that is: Digital Society, and a Healthy, secure and safe society. The representatives of the business sector suggested focusing on themes that were cross-cutting the top sectors that had been defined earlier as the focus areas for the Netherlands. Their focus is on smart cities, circular economy, smart industry, sustainable food production, and energy transition. The medical centres have suggested focusing on personalised medicine and regenerative health care.

The knowledge coalition and other stakeholders have called on the government to provide extra budgets for science and to implement the agenda. In 2018 the (still relatively new) coalition government officially launched the agenda after the announcement earlier this year of additional 
funds for research. Policies were developed about the calls for proposals on the research themes included in the Agenda.

A crucial element in the National Research Agenda is its attention for collaboration - in terms of public-private partnerships (PPPs) as well as in terms of cross-disciplinary research - and its focus on societal challenges. Concerns are expressed when it comes to the situation of individual disciplines (e.g. humanities, mathematics, law) and the support of individual researchers. Another issue is the need for matching funds when undertaking large projects in public-private research consortia. With more resources becoming available for projects, some fear that less is left for individuals undertaking curiosity-based research.

The Dutch research council (NWO) recently published its new strategy for the period 20192022. The strategic plan describes five ambitions to facilitate the scientific and societal impact of Dutch research in the coming years. NWO's ambitions are as follows:

1. Nexus role: connecting agendas, science and society

2. People: perspective for researchers

3. Research: collaboration for excellence and innovation

4. Infrastructure: accessible and sustainable scientific infrastructure

5. Knowledge sharing: effective use of knowledge through co-design and co-creation

NWO's renowned Talent Scheme (Rubicon, Veni, Vidi, Vici) will be supplemented with instruments by which talented researchers can continue working on existing research with a longer duration, whether alone or with a team. Furthermore, the NWO Open Competition for curiosity-driven research will be given a modular structure.

NWO will implement the Dutch National Research Agenda. Programmes in the Dutch National Research Agenda will be set up across the breadth of science and provide opportunities for a 
broad knowledge chain approach in which fundamental, strategic, practice-oriented and applied research will be connected with each other, where relevant. Non-scientific parties will also have the opportunity to be involved in realising research in these programmes. NWO will place a considerable emphasis on collaboration - for instance through public-private and public-public partnership in research.

NWO will extend the programme Industrial Doctorates that is aimed at collaboration between knowledge institutions and companies. Analogous to this, the programme Societal Doctorates will be established for collaboration with public partners. Furthermore, a proof-of-concept grant will be established that will allow researchers to explore the societal potential of research previously funded by NWO.

Recently the KNAW produced two reports looking at the quality of the Dutch research system:

1. Van Dijck, J. and W. van Saarloos (2017), The Dutch Polder Model in science and research. What allowed the Netherlands to punch above its weight? How should the country build on that achievement?

2. KNAW (2018), De aantrekkelijkheid van Nederland als onderzoeksland (with an English summary). 


\section{References/further reading}

AWT (2003), Backing winners. From generic technology policy to active innovation policy. Den Haag; AWT. Available online at: https://english.awti.nl/documents/publications/2003/7/30/backing-winners

Van Dijck, J. and W. van Saarloos (2017), The Dutch Polder Model in science and research. What allowed the Netherlands to punch above its weight? How should the country build on that achievement? Amsterdam: KNAW. Available online at: https://www.knaw.nl/en/news/publications/the-dutch-polder-model-in-science-andresearch

European Commission (EC) (2016), Horizon 2020 Monitoring Report 2015. Brussels. Available online at: http://ec.europa.eu/research/evaluations/pdf/archive/h2020_monitoring_reports/second h2020_annual_monitoring_report.pdf

European Union (2017), European Innovation Scoreboard 2017, Brussels. Available online at: https://www.rvo.nl/sites/default/files/2017/06/European_Innovation_Scoreboard_2017 . pdf

Kenniscoalitie (2015), Nationale Wetenschapsagenda. Vragen, verbindingen, vergezichten. The Hague: NWO. English version available online at: https://wetenschapsagenda.nl/publicatie/dutch-national-research-agendaenglish/?lang=en

KNAW (2014), Standard Evaluation Protocol 2015 - 2021. The Hague: KNAW. Available online at: https://www.vsnu.nl/files/documenten/Domeinen/Onderzoek/SEP20152021.pdf

KNAW (2018), De aantrekkelijkheid van Nederland als onderzoeksland. Amsterdam: KNAW. Available online at: https://www.knaw.nl/shared/resources/actueel/publicaties/pdf/20180129-advies-deaantrekkelijkheid-van-nederland-als-onderzoeksland 
Ministry of Education, Culture and Science (2014), Wetenschapsvisie 2025. Keuzes voor de Toekomst. The Hague: Ministry of Education, Culture and Science. Available online at: https://www.rijksoverheid.nl/binaries/rijksoverheid/documenten/rapporten/2014/11/25 /wetenschapsvisie-2025-keuzes-voor-de-toekomst/wetenschapsvisie-2025-keuzesvoor-de-toekomst.pdf

Ministry of Education, Culture and Science (2015), De waarde(n) van weten: Strategische Agenda Hoger Onderwijs en Onderzoek 2015-2025. The Hague: Ministry of Education, Culture and Science. Available online at: https://www.rijksoverheid.nl/documenten/kamerstukken/2015/07/07/aanbieding$\underline{\text { strategische-agenda-hoger-onderwijs-en-onderzoek }}$

Ministry of Education, Culture and Science (2017), Wetenschap met impact. Letter to Parliament, dated January 19, 2017. The Hague: Ministry of Education, Culture and Science. Available online at: https://www.rijksoverheid.nl/documenten/kamerstukken/2017/01/19/kamerbrief-overwetenschap-met-impact

Ministry of Economic Affairs (2004), Peaks in the Delta. Regional Economic Perspectives. The Hague: Ministry of Economic Affairs. Available online at: http://www.eprc.strath.ac.uk/benchmarking2/documents/Peaks_in_the_Delta.pdf

Ministry of Education, Culture and Science (2014), Wetenschapsvisie 2025: Keuzes voor de toekomst. The Hague: Ministry of Education, Culture and Science. Available online at: https://www.rijksoverheid.nl/documenten/rapporten/2014/11/25/wetenschapsvisie$\underline{\text { 2025-keuzes-voor-de-toekomst }}$

OECD (2014), OECD Reviews of Innovation Policy: Netherlands 2014. OECD Publishing. Available online at: http://www.oecd.org/sti/inno/netherlands-innovation-reviewrecommendations.pdf 
Rathenau Instituut (2008), Facts and Figures: Universities in the Netherlands. The Hague: Rathenau Instituut.

Rathenau Instituut (2016), Balans van de Wetenschap 2016. Den Haag: Rathenau. Available at: https://www.knaw.nl/nl/actueel/publicaties/balans-van-de-wetenschap2016/@@download/pdf_file/BalansVanDeWetenschap\%202016.pdf

Review Committee / Higher Education and Research Review Committee (2017), System report 2016. Fourth annual monitoring report on the progress of the profiling and quality improvement process in higher education and research. The Hague: Review Committee. Available online at: http://www.rcho.nl/images/Stelselrapportage$\underline{\text { Reviewcommissie-2016-Engels.pdf }}$ 
The Center for Higher Education Policy Studies (CHEPS) is a research institute (WHW, Article 9.20) located in the Faculty of Behavioural and Management Sciences within the University of Twente, a public university established by the Dutch government in 1961. CHEPS is a specialized higher education policy centre that combines basic and applied research with education, training and consultancy activities.

http://www.utwente.nl/bms/cheps/

$|c| h|l| p|s|$

Center for Higher Education

Policy Studies 